\title{
Penerapan Tingkat Minat Baca Siswa SD Inpres 037145 Menggunakan K-Means
}

\author{
Anita $^{1}$, Herwin Simbolon ${ }^{2}$ \\ Program Studi Sistem Informasi Fakultas Teknologi dan Ilmu Komputer Universitas Prima \\ Indonesia ${ }^{1,2}$ \\ Email : anitayakub_pilchan@yahoo.com ${ }^{1}$ \\ DOI: http://dx.doi.org/10.31869/rtj.v4i2.2556
}

\begin{abstract}
Grouping students' reading interest based on the criteria for books read, books borrowed, and also considering the number of books available can help in the process of adding to the existing book collection in the library. One way to manage this data is by using data mining by utilizing the $\mathrm{K}$ Means method. Book data are grouped into 3 clusters, namely priority, consideration, and not prioritization in planning for additional book collections. The result of this research is that the cluster with the largest value in the final centroid is the recommended cluster in planning to add to the book collection.
\end{abstract}

Keywords: clustering, k-means, data, library

Abstrak: Pengelompokkan minat baca mahasiswa berdasarkan kriteria buku yang dibaca, buku yang dipinjam, dan juga mempertimbangkan jumlah stok buku yang tersedia dapat membantu dalam proses penambahan koleksi buku yang telah ada pada perpustakaan. Salah satu cara untuk mengelola data tersebut yaitu menggunakan data mining dengan memanfaatkan metode K-Means. Data buku dikelompokkan menjadi 3 cluster yaitu prioritas, dipertimbangkan, dan tidak diprioritaskan dalam perencanaan penambahan koleksi buku. Hasil dari penelitian ini adalah cluster dengan nilai terbesar pada centroid akhir merupakan cluster yang direkomendasikan dalam perencanaan penambahan koleksi buku.

Kata Kunci: clustering, $k$-means, data, perpustakaan

\section{PENDAHULUAN}

Minat baca merupakan suatu pengaruh yang besar bagi siswa. Dalam meningkatkan upaya minat baca siswa sekolah dasar menjadi tanggung jawab bersama, antara siswa itu sendiri, guru maupun orang tua. Namun rendahnya minat baca siswa di sekolah dasar menjadi salah satu halangan, kurangnya keinginan dan kemauan dari siswa itu sendiri, guru juga belum mengharuskan siswa untuk membaca buku saat pembelajarn yang diajarkan kepada siswa. Dalam upaya meningkatkan minat baca siswa sekolah dasar sebaiknya siswa diberi dukungan agar minat baca itu muncul dari diri siswa dan perpustakaan sebagai tempat menyimpan koleksi bahan pustaka sumber informasi.

Pada Saat ini, sistem yang diterapkan di perpustakaan SD INPRES 037145 berjalan kurang efektif. Ini terlihat dari mulai tahap perencanaan yang meliputi pemilihan hingga penambahan koleksi buku yang tidak maksimal sehingga minat baca siswa berkurang. Salah satu cara untuk mengelola data tersebut yaitu dengan menggunakan data mining. Penerapan data mining telah banyak digunakan dalam pengelolahan data untuk menghasilkan pengetahuan, salah satunya [1] Algoritma K-Means Clustering yang telah digunakan dalam berbagai kasus pengelompokan data untuk peminatan literasi [2], Selain itu untuk mengetahui proporsi mengelompokkan literasi yang layak dalam SD INPRES 037145 [3] sehingga k-means dapat sebagai alat bantu untuk menentukan literasi yang bagus.

\section{METODOLOGI PENELITIAN \\ Data Mining}

Data Mining merupakan suatu istilah yang digunakan untuk mendapatkan pengetahuan yang tersembunyi dari kumpulan data yang berukuran sangat besar. yang tujuan utama Data Mining adalah untuk

menemukan, menggali, atau menambang pengetahuan dari data atau informasi yang kita miliki[4] .

\section{Metode K-Means Clustering}

Metode K-means clustering merupakan metode clustering yang dikenalkan oleh Metode $K$-means adalah metode yang terkenal cepat dan simpel. K-means clustering merupakan salah satu metode data clustering 
non hirarki yang mengelompokan data dalam bentuk satu atau lebih cluster/kelompok. Datadata yang memiliki karakteristik yang sama dikelompokan dalam satu cluster/kelompok dan data yang memiliki karakteristik yang berbeda dikelompokan dengan cluster/kelompok yang lain sehingga data yang berada dalam satu cluster/kelompok memiliki tingkat variasi yang kecil [5]. Langkahlangkah melakukan clustering dengan metode K-means adalah sebagai berikut:

1. Pilih jumlah cluster $\mathrm{k}$.

2. Inisialisasi ke pusat cluster ini bisa dilakukan dengan berbagai cara. Cara yang paling sering dilakukan adalah dengan random atau acak. Pusat-pusat cluster diberi dengan nilai awal dengan angkaangka random

3. Alokasikan semua data/objek ke cluster terdekat. Kedekatan dua objek ditentukan berdasarkan jarak ke-dua objek tersebut.

\section{HASIL DAN PEMBAHASAN}

Dari langkah-langkah dan urutan prosedur dari suatu program kerja secara keseluruhan menggunakan metode K-Means mulai dari awal sampai akhir prosesnya. Berikut ini adalah gambar Flowchartnya algoritma $K$ Means yaitu sebagai berikut:

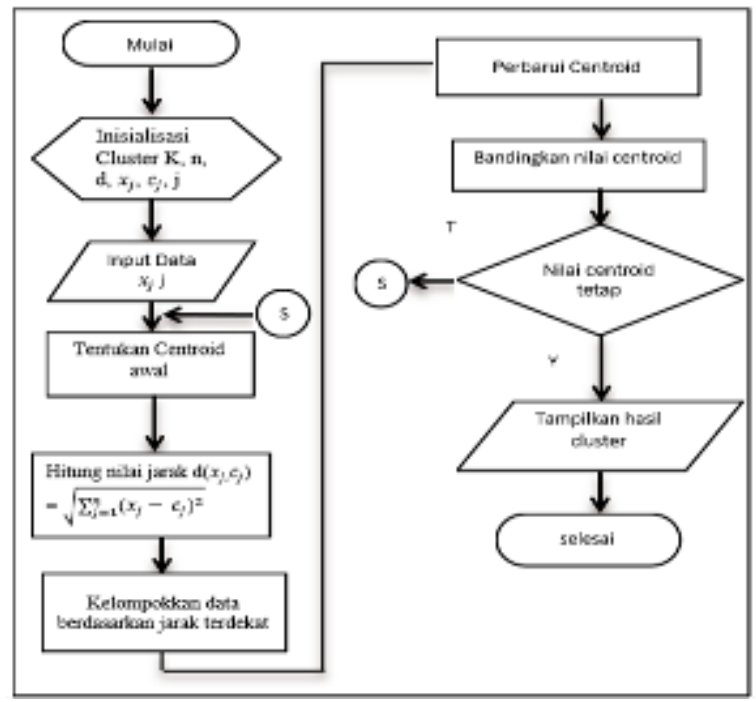

Gambar 1 Flowchart Algoritma K-Means

Data yang menyangkut dengan Peminatan literasi baca SD INPRES 037145 adalah sebagai berikut :
Tabel 1 Data Laporan Jumlah Siswa

Peminatan Literasi baca Buku Dalam Peminjaman

\begin{tabular}{|c|c|c|c|c|}
\hline No & Nama Siswa & $\begin{array}{c}\text { Buku Mata } \\
\text { Pelaiaran }\end{array}$ & $\begin{array}{l}\text { Buku } \\
\text { Cerita }\end{array}$ & $\begin{array}{c}\text { Buku } \\
\text { Umum }\end{array}$ \\
\hline 1 & $\begin{array}{l}\text { M Zulfiker } \\
\text { Surya }\end{array}$ & 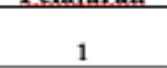 & 2018 & क्ष \\
\hline 2 & $\begin{array}{l}\text { Mhd Khairuddin } \\
\text { Lubis }\end{array}$ & 4 & 3 & 2 \\
\hline 3 & $\begin{array}{l}\text { Rusdina } \\
\text { Hatimuh }\end{array}$ & 10 & 7 & 8 \\
\hline 4 & $\begin{array}{l}\text { Desi Wrdani } \\
\text { Samara }\end{array}$ & 2 & 4 & 6 \\
\hline 5 & $\begin{array}{l}\text { Anto Syahputra } \\
\text { Barus }\end{array}$ & 3 & 4 & 3 \\
\hline 6 & $\begin{array}{l}\text { Muhammad } \\
\text { Rizki Faiar }\end{array}$ & 1 & 1 & 1 \\
\hline 7 & $\begin{array}{l}\text { Finky } \\
\text { Handayani }\end{array}$ & 2 & 1 & 5 \\
\hline 8 & $\begin{array}{l}\text { Fahry } \\
\text { Muhammad }\end{array}$ & 1 & 1 & 1 \\
\hline 9 & $\begin{array}{l}\text { Alfredo } M \\
\text { Sembiring }\end{array}$ & 2 & 5 & 5 \\
\hline 10 & $\begin{array}{l}\text { Agustina Ratna } \\
\text { Sari }\end{array}$ & 3 & 5 & 5 \\
\hline \multicolumn{5}{|c|}{ Larjiutan sarnpai nomos 150} \\
\hline 150 & Dede Amelia & 2 & 4 & 6 \\
\hline
\end{tabular}

Data pada tabel data 1 di atas agar dapat diolah menggunakan algoritma K-Means, maka dinormalisasikan atau membersihkan data yang tidak digunakan serta menginisialkan data pengiriman dan alamat dengan ketentuan, Berikut ini langkah-langkah pada algoritma $K$-Means sampai diketahui pembagian nilai Centroid sebelumnya tidak berubah.

1. Menentukan jumlah Cluster misalkan sebanyak $k=3$

2. Menentukan Centroid $c$ setiap Clusteryang diambil dari data sumber.

Table 2 Tabel Data Centroid Awal

\begin{tabular}{|c|c|c|c|}
\hline Centroid & $\begin{array}{c}\text { Pembelajaran } \\
\text { Umum }\end{array}$ & $\begin{array}{c}\text { Bnku } \\
\text { Cerita }\end{array}$ & Fiksi \\
\hline Centroid 1 & 1 & 1 & 1 \\
\hline Centroid 2 & 3 & 4 & 3 \\
\hline Centroid 3 & 10 & 7 & 8 \\
\hline \multicolumn{4}{|c|}{ Hitung jarak data ke Centroid }
\end{tabular}
menggunakan rumus Euclidean, data tersebut dari Cluster terdekatnya.

a. Jarak antara siswa nomor pertama dengan titik $\mathrm{m} 1$

$$
\begin{aligned}
& =\sqrt{\sum_{i=1}^{n}\left(x_{i}-y_{i}\right)^{2}} \\
= & \sqrt{(1-1)^{2}+(1-121)^{2}+(1-21)^{2}} \\
= & 0
\end{aligned}
$$

b. Jarak antara siswa nomor kedua dengan titik $\mathrm{m} 1$

$$
=\sqrt{\sum_{i=1}^{n}\left(x_{i}-y_{i}\right)^{2}}
$$


Vol. 4 No.2 Juni 2021

http://jurnal.umsb.ac.id/index.php/RANGTEKNIKJOURNAL

$=\sqrt{(4-1)^{2}+(3-1)^{2}+(2-1)^{2}}$

$=4,123$

c. Jarak antara siswa nomor ketiga dengan titik $\mathrm{m} 1$

$$
=\sqrt{\sum_{i=1}^{n}\left(x_{i-} y_{i}\right)^{2}}
$$

$$
=\sqrt{(10-1)^{2}+(7-1)^{2}+(8-1)^{2}}
$$

$=12,884$

d. Jarak antara siswa nomor pertama dengan titik $\mathrm{m} 2$

$$
=\sqrt{\sum_{i=1}^{n}\left(x_{i}-y_{i}\right)^{2}}
$$

$=\sqrt{(1-3)^{2}+(1-4)^{2}+(1-3)^{2}}$

$$
=3,742
$$

e. Jarak antara siswa nomor kedua dengan titik $\mathrm{m} 2$

$$
=\sqrt{\sum_{i=1}^{n}\left(x_{i}-y_{i}\right)^{2}}
$$

$$
=\sqrt{(4-3)^{2}+(3-4)^{2}+(2-3)^{2}}
$$

$$
=1,732
$$

f. Jarak antara siswa nomor ketiga dengan titik $\mathrm{m} 2$

$$
=\sqrt{\sum_{i=1}^{n}\left(x_{i-} y_{i}\right)^{2}}
$$

$$
\begin{gathered}
=\sqrt{(10-3)^{2}+(7-4)^{2}+(8-3)^{2}} \\
=9,381
\end{gathered}
$$

g. Jarak antara siswa nomor pertama dengan titik $\mathrm{m} 3$

$$
=\sqrt{\sum_{i=1}^{n}\left(x_{i}-y_{i}\right)^{2}}
$$

$$
\begin{aligned}
& =\sqrt{(1-10)^{2}+(1-7)^{2}+(1-8)^{2}} \\
& =12,884 \\
& \text { h. Jarak antara siswa nomor kedua }
\end{aligned}
$$

\begin{tabular}{|c|c|c|c|c|c|}
\hline $\mathrm{Y}_{0}$ & Nama Siswa & $\mathrm{Cl}$ & $\mathrm{C} 2$ & $\mathrm{C}^{3}$ & $\begin{array}{c}\text { JARAK } \\
\text { TERDEKAT }\end{array}$ \\
\hline 1 & M Zulfilsor Suryz & 0,000 & 4,123 & 12,854 & $\mathrm{Cl}$ \\
\hline 2 & Mhd Khainustin Luhis & 3,742 & 1,732 & 9,381 & $\mathrm{C} 2$ \\
\hline 3 & Rusfina Halimsh & 12884 & 9,110 & 0,000 & $\mathrm{CH}$ \\
\hline 4 & Desi Wrdani Sumura & 5,916 & 3,162 & 8.775 & $\mathrm{C}_{2}$ \\
\hline 5 & Anto Syahprena Berts & 4,123 & 0,000 & 9,110 & $\mathrm{C} 2$ \\
\hline 6 & Mukermad Rizki Feiar & 0.000 & 4,123 & 12,854 & $\mathrm{Cl}$ \\
\hline 7 & Finky Handayani & 4,123 & 3,742 & 10,40 & $\mathrm{C} 2$ \\
\hline 8 & Faltry Mubsmmad & 0,000 & 4,123 & 12,854 & $\mathrm{Cl}$ \\
\hline 9 & Alfreds M Sembirinz: & 5,745 & 2,449 & 8,775 & $\mathrm{C} 2$ \\
\hline 10 & Agrstina R2tm2 San & 6,000 & 2,236 & 7,874 & $\mathrm{C} 2$ \\
\hline \multicolumn{6}{|c|}{ Linivian sampai $=0 \mathrm{mos} 150$} \\
\hline 150 & Dede Amelia & 5.916 & 3,162 & 8.735 & $\mathrm{C2}$ \\
\hline
\end{tabular}
dengan titik $\mathrm{m} 3$

$$
\begin{aligned}
& =\sqrt{\sum_{i=1}^{n}\left(x_{i-} y_{i}\right)^{2}} \\
= & \sqrt{(4-10)^{2}+(3-7)^{2}+(2-8)^{2}} \\
= & 9,110
\end{aligned}
$$

i. Jarak antara siswa nomor ketiga dengan titik $\mathrm{m} 3$

$$
=\sqrt{\sum_{i=1}^{n}\left(x_{i}-y_{i}\right)^{2}}
$$

$$
\begin{gathered}
=\sqrt{(10-10)^{2}+(7-7)^{2}+(8-8)^{2}} \\
=0
\end{gathered}
$$

Untuk lebih lengkapnya jarak pada setiap baris data, hanya ditampilkan 10 dari 150 data seperti pada tabel berikut:

Tabel 3 Tabel Hasil Perhitungan Iterasi Ke 1 (Lanjutan)

Dari tabel 3 di dapat Jumlah Siswa sebagai berikut :

$$
\text { - } \quad \mathrm{C} 1=\{
$$

$1,6,8,13,15,18,22,25,27,31,32,39$, $47,48,55,63,64,71,79,80,87,95,96$, $103,111,112,119,126,127,134,138$ $, 139,146\}$

- $\mathrm{C} 2=\{$

$2,4,5,7,9,10,11,12,14,16,17,19,20$, $21,23,24,26,28,29,30,33,34,35,36$, $37,38,40,41,43,44,45,46,49,50,51$, $53,54,56,57,59,60,61,62,65,66,67$, $69,70,72,73,75,76,77,78,81,82,83$, $85,86,88,89,91,92,93,94,97,98,99$, $101,102,104,105,107,108,109,110$ ,113,114,115,117,118,120,121,12 $3,124,125,128,129,130,132,133,1$ $35,136,137,140,141,142,144,145$, $147,148,150\}$

- $\mathrm{C} 3=$ $3,42,52,58,68,74,84,90,100,106,1$ $16,122,131,143,149\}$

- Lakukan pembaruan Centroid dari hasil Cluster seperti berikut :

- $\quad \mathrm{C} 1$ = rata-rata $(1,6,8,13,15,18,22,25,27,31,32,39$, 


$$
\begin{aligned}
& 47,48,55,63,64,71,79,80,87,95,96, \\
& 103,111,112,119,126,127,134,138, 139,146) \\
&=(1 ; 1 ; 1) \\
&-\mathrm{C} 2=\text { rata-rata } \\
&(2,4,5,7,9,10,11,12,14,16,17,19,20,2 \\
& 1,23,24,26,28,29,30,33,34,35,36,37, \\
& 38,40,41,43,44,45,46,49,50,51,53,5 \\
& 4,56,57,59,60,61,62,65,66,67,69,70, \\
& 72,73,75,76,77,78,81,82,83,85,86,8 \\
& 8,89,91,92,93,94,97,98,99,101,102, \\
& 104,105,107,108,109,110,113,114,1 \\
& 15,117,118,120,121,123,124,125,12 \\
& 8,129,130,132,133,135,136,137,140 \\
&, 141,142,144,145,147,148,150) \\
& \quad=(2.66 ; 4.00 ; 4.55) \\
& \text { C3 }=\text { rata-rata } \\
&(3,42,52,58,68,74,84,90,100,106,1 \\
&16,122,131,143,149) \\
& \quad=(10 ; 7 ; 8)
\end{aligned}
$$

\begin{tabular}{|c|c|}
\hline Claster & Nomer \\
\hline $\begin{array}{l}\text { Sisma Peminateo Literasi } \\
\text { baca Rendah }\end{array}$ & $\begin{array}{l}\mathrm{I}, 61,8,13,15,18,22,25,27,3 \mid, 32,39,47,48,55,63,64,71,79, \\
80,87,95,96,103,111,112,119,126,127,134,138,139,146\end{array}$ \\
\hline $\begin{array}{l}\text { Sisma Peminatan Literasi } \\
\text { baca Sodeng }\end{array}$ & $\begin{array}{l}2,4,5,79,10,11,12,14,16.17,19,20,21,23,24,26,28,29,30, \\
33,34,35,96,37,38,40,41,43,44,45,461,49,50,51,53,54,56, \\
57,59,60,61,62,65,66,67,69,70,72,73,75,76,77,78,81,82, \\
83,85,86,88,89,91,92,93,9497,98,99,101,102,104,105,1 \\
07,108,109,110,113,114,115,117,118,120,121,123,124, \\
125,128,129,130,132,133,135,136,1.37,1140,141,142,144 \\
, 145,147,148,190\end{array}$ \\
\hline $\begin{array}{c}\text { Sissa Peminatgo Literasi } \\
\text { bsca Tingei }\end{array}$ & $3,42,52,58,68,74,84,90,100,105,116,122,131,143,149$ \\
\hline
\end{tabular}

Menghitung kembali nilai rasio dengan membandingkan nilai $B C V$ dan $W C V$.

$$
\begin{aligned}
B C V / W C V & =26,118 / 225,602 \\
& =0,116
\end{aligned}
$$

Nilai Centroid berubah dari nilai Centroid sebelumnya, maka algoritma dilanjutkan ke langkah berikutnya.

Hasil pengelompokkan cluster dari minat baca literasi baca rendah adalah sebagi berikut:

Tabel 4 Pengelompokkan Hasil Cluster

\section{Tampilan Program}

1. Form Login

Form Login merupakan form untuk melakukan pengisian data awal user sebelum masuk ke Form Menu Utama. Form Login ini bertujuan untuk mengamankan sistem dari user-user yang tidak bertanggung jawab. Pada form ini, yang dilakukan adalah menginput User dan Password dengan benar dan sesuai dengan data yang telah di daftarkan pada database login. Berikut adalah tampilan Form Login :

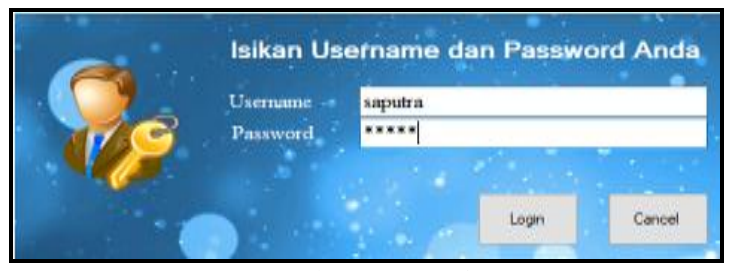

Gambar 2 Login

\section{Form Menu Utama}

Form Menu Utama digunakan sebagai penghubung untuk Form Data Siswa, Form Input Data Centroid, Form proses K-Means, dan Form Laporan Cluster. Di Dalam Form Menu Utama ini terdapat beberapa menu yang dimana diantaranya adalah menu Data Untuk menampilkan Form Data Siswa dan Form Input Data Centroid, menu proses untuk menampilkan Form Proses K-Means, menu Laporan Cluster untuk menampilkan Form Laporan Hasil Perhitungan Proses K-Means dan Menu Keluar untuk menutup aplikasi. Berikut adalah tampilan Form Menu Utama :

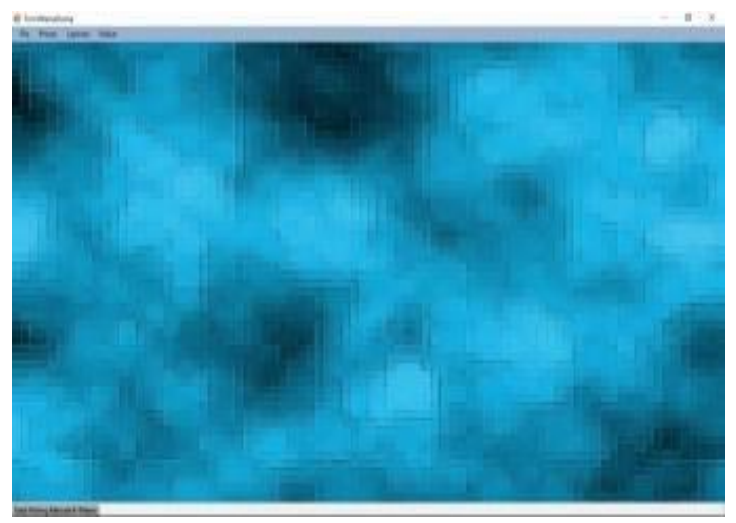

Gambar 2 Tampilan Utama

\section{Form Data Siswa}

Form Data Siswa adalah Form pengolahan Data Siswa dalam menginput data, menyimpan data, mengubah data dan menghapus data. Adapun Form Data Siswa adalah sebagai berikut :

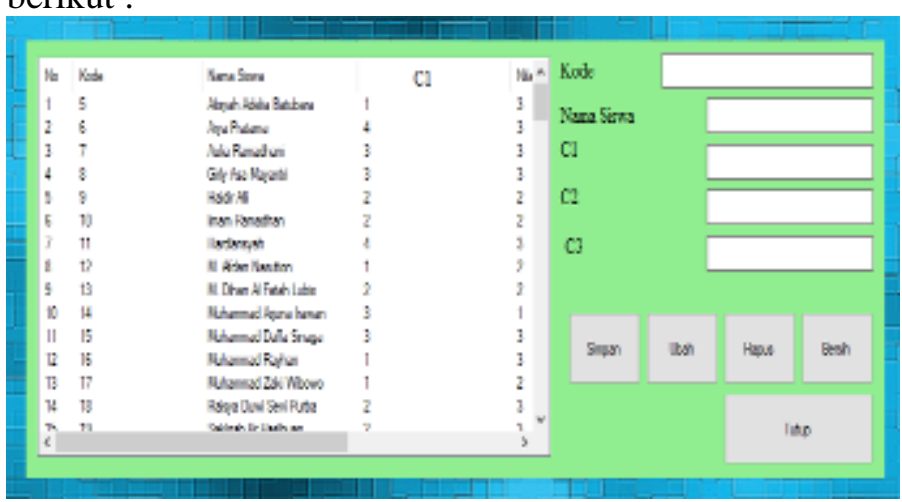

Gambar 4 Tampilan Data Siswa 


\section{Form Input Nilai Centroid}

Form Input Nilai Centroid adalah pengolahan data Centroid yang dapat di ubah jika Nilai Centroidnya ditentukan dengan Nilai Centroid yang berbeda. Adapun Form Input Nilai Centroid adalah sebagai berikut :

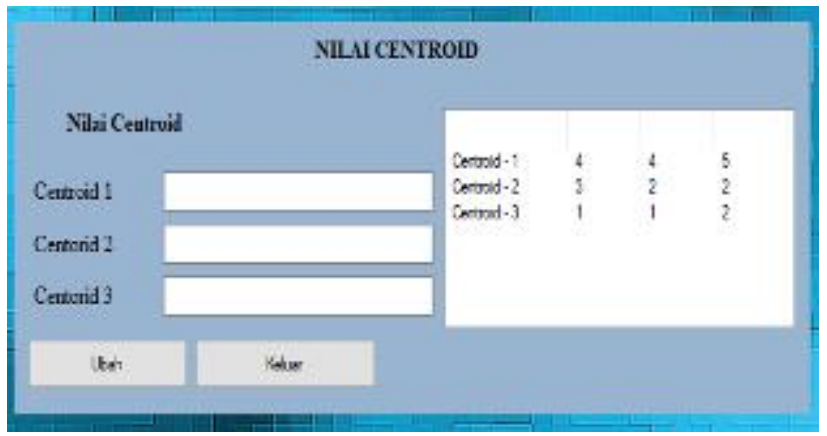

Gambar 5 Tampilan Input Nilai Centroid

\section{Form Metode K-Means}

Form Metode K-Means adalah proses perhitungan dalam mengelompokkan data dalam mengelompokkan data berdasarkan variabel yang sudah ditentukan. Adapun Form Metode $K$-Means adalah sebagai berikut :

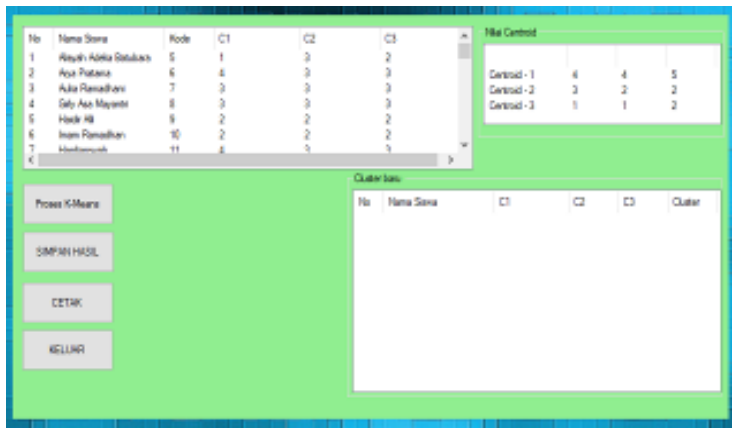

Gambar 6 Tampilan Metode K-Means

\section{Form Cluster}

Form Cluster adalah proses pengelompokkan data cluster sesuai variabel yang sudah ditentukan. Adapun Form Cluster adalah sebagai berikut :

\begin{tabular}{|c|c|c|c|c|c|}
\hline Row No. & id & cluster & $\mathrm{C}_{1}$ & $c 2$ & c3 \\
\hline 104 & 104 & cluster_o & 3 & 1 & 2 \\
\hline 105 & 105 & cluster_1 & 3 & 2 & 2 \\
\hline 106 & 106 & cluster_z & 2 & 3 & 2 \\
\hline 107 & 107 & cluster_-1 & 4 & 3 & 4 \\
\hline 108 & 108 & cluster_2 & 2 & 3 & 2 \\
\hline 109 & 109 & cluster_o & 2 & 2 & 2 \\
\hline 110 & 110 & cluster_o & 3 & 2 & 1 \\
\hline 111 & 111 & cluster_o & 3 & 1 & 3 \\
\hline 112 & 112 & cluster_o & 1 & 2 & 3 \\
\hline 113 & 113 & cluster_z & 1 & 3 & 2 \\
\hline 114 & 114 & cluster_-1 & 3 & 3 & 3 \\
\hline 115 & 115 & cluster_2 & 2 & 3 & 3 \\
\hline 116 & 116 & cluster_1 & 4 & 2 & 2 \\
\hline 117 & 117 & cluster_o & 1 & 2 & 2 \\
\hline 118 & 118 & cluster_o & 2 & 2 & 2 \\
\hline 119 & 119 & cluster_-1 & 3 & 2 & 2 \\
\hline 120 & 120 & cluster_ 1 & 3 & 3 & 4 \\
\hline
\end{tabular}

\section{Data Cluster}

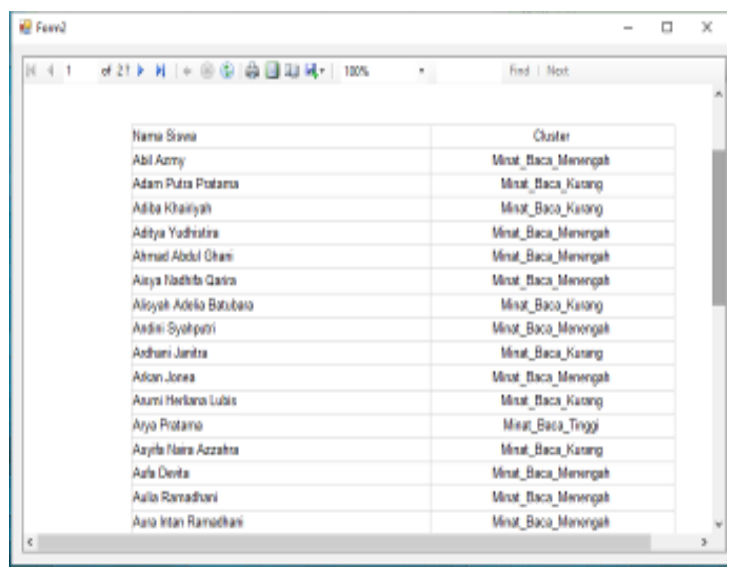

Gambar 8 Tampilan hasil Cluster

7. Hasil yang ditampilkan di program sistem Berikut ini adalah hasil dari tampilan di program sistem, adalah sebagai berikut :

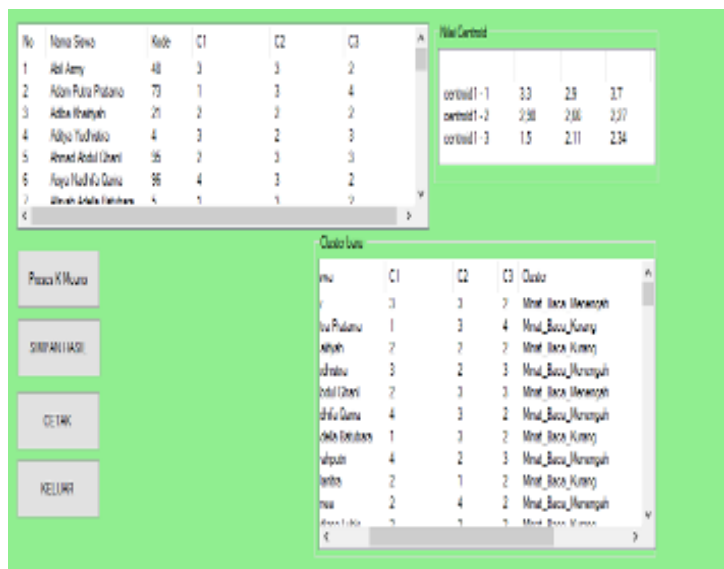

Gambar 9 Tampilan hasil yang ditampilkan di program sistem

\section{PENUTUP \\ Simpulan}

Berdasarkan hasil analisa dari permasalahan yang terjadi dengan kasus yang di bahas tentang mengelompokan minat baca dengan menerapakan algoritma k-means terhadap sistem yang dirancang dan dibangun maka dapat ditarik kesimpulan sebagai berikut:

1. Dalam mengelompokkan metode $k$-means dapat digunakan untuk mepersingkat siswa mana yang berminat baca dan mengetahui buku apa yang diminati oleh siswa.

2. Dapat merancang sistem dengan menggunakan Class diagram, alur sistem dengan aktor dengan menggunakan activity diagram ataupun use case 
diagram dan alur algoritma sistem menggunakan flowchart.

3. Dapat menguji sistem dengan menggunakan bahasa pemograman visual basic dan mepercepat dalam pengelompokkan data.

\section{Saran}

Untuk meningkatkan kemampuan dan fungsi dari sistem ada beberapa saran yang sdapat diberikan untuk pengembangan yang bisa dilakukan yaitu :

1. Sistem yang dirancang dan dibangun harus dikembangkan lagi dengan berbasis Mobile dan web.

2. Disarankan sistem tidak hanya menggunakan algoritma k-means akan tetapi bisa dipadukan dengan algoritma yang lain ataupun dengan kombinasi yang lain untuk meningkat keakuratan dalam pengelompokkan.

3. Disarankan data yang digunakan dengan mengunakan lebih dari 1 tempat riset yang dikelompokkan dapat meninkatkan tingkat keakuratan pengelompokkan.

\section{DAFTAR PUSTAKA}

[1] D. Sunia, K. and A. P. Jusia, "Penerapan Data mining Untuk Clustering Data Penduduk Miskin Menggunakan Algoritma K-Means," STIKOM Dinamika Bangsa, pp. 121-134, 2019.

[2] S. S. Helma, M. R. R. R and E. Normala, "Clustering pada Data Fasilitas Pelayanan Kesehatan Kota Pekanbaru Menggunakan Algoritma K-Means," Seminar Nasional Teknologi Informasi, Komunikasi dan Industri (SNTIKI, vol. I, no. 1, pp. 131-137, 2019.

[3] F. Yunita, "Penerapan Data mining Menggunkan Algoritma K-Means Clustring Pada Penerimaan Mahasiswa Baru (Studi Kasus : Universitas Islam Indragiri)," Jurnal SISTEMASI, pp. 238-249, 2018.

[4] Alfannisa Annurullah Fajrin and Algifanri Maulana, "Penerapan Data mining Untuk Analisis Pola Pembelian Konsumen Dengan Algoritma Fpgrowth Pada Data Transaksi Penjualan Spare Part Motor," Kumpulan jurnaL Ilmu Komputer
(KLIK), vol. Volume 05, 2018

[5] Joko Suntoro, Data mining: Algoritma Dan Implementasi Dengan Pemrograman, Elex Media Komputindo, 2019, p. 192.

[6] S. Kasiyun, "Upaya Meningkatkan Minat Baca Sebagai Sarana Untuk Mencerdaskan Bangsa," JURNAL PENA INDONESIA (JPI), vol.I No.1, 2015

[7] A. Kurniawan , D. , S. Hayati, R. , J. Riskayanti, I. Wasena, Y.Triadi., "Peranan Pojok Baca dalam Menumbuhkan Minat Baca Siswa Sekolah Dasar," JURNAL INOVASI PENDIDIKAN DAN PEMBELAJARAN SEKOLAH DASAR, vol.III No.2, 2019 